\title{
MERCADO CAMBIAL CONTEMPORÂNEO
}

\author{
Marcos Roberto Vasconcelos*
}

\section{INTRODUÇÃO}

Desde o desmanche de Bretton Woods em 1973, quando as principais moedas nacionais (dólar americano, marco alemão e iene) passaram a manter paridades flutuantes entre si, observam-se alto grau de volatilidade cambial e longos períodos de desalinhamentos destas paridades que não são passíveis de explicação pela análise dos chamados fundamentos cambiais - diferenciais de juros, de inflação e de renda, saldos em transações correntes etc. (FRANKEL; ROSE, 1994). Causou surpresa tal comportamento, pois, à primeira vista e em termos simplificados, os mercados de câmbio podem ser tratados tão-somente como locus nos quais se realizam as operações de conversão entre as diversas moedas nacionais, sendo a taxa de câmbio mera expressão desta conversão e resultado da oferta e da demanda relativa de cada divisa. Tais operações refletiriam as transações comerciais (bens e serviços) e financeiras (empréstimos e investimentos) entre agentes econômicos residentes em distintos países, pautadas e determinadas por avaliações dos fundamentos cambiais, orientadores das decisões relativas ao comércio internacional e às aplicações financeiras interfronteiras. Neste sentido, os mercados de divisas deveriam ser tratados apenas como o reflexo ou a contraparte monetária das transações internacionais realizadas em outros mercados, não possuindo assim uma dinâmica autônoma, e a taxa de câmbio a expressão última de alterações dos fundamentos cambiais.

Entretanto, ao se examinar mais detalhadamente o comportamento

"Doutor em economia pelo IE-Unicamp e professor do Departamento de Economia da Universidade Estadual de Maringá. Agradeço a Fernando Nogueira da Costa e a Eduardo Strachman pelos comentários e sugestões. 
do mercado internacional de câmbio nas últimas duas décadas, emergem não apenas os fenômenos de períodos de intensa volatilidade e de largos desalinhamentos nas paridades cambiais, mas também o reconhecimento da sua eloqüente expansão em termos de volume de negócios e do seu dinamismo transformacional, cujas motivações e implicações podem ser obliteradas em uma análise mais superficial. Como expresso no primeiro parágrafo, é no mercado cambial que se definem as paridades de troca entre as moedas nacionais. Conforme o entendimento que se tenha da sua lógica de funcionamento, desdobram-se os pressupostos teóricos para a determinação destas paridades e de outros fenômenos relacionados. Daí a importância de aprofundar-se o conhecimento sobre o mercado internacional de câmbio e explicitar as suas particularidades microestruturais. Os agentes atuantes nos mercados cambiais, os instrumentos e mecanismos de que eles dispõem para realizar suas operações, os sistemas eletrônicos de distribuição de informação e de comercialização de ativos, os heterogêneos processos de formação das expectativas, o imbricamento e a interação entre os distintos mercados cambiais nacionais e entre os agentes intramercado, as transformações dos mercados financeiros, entre outras, são algumas das questões pertinentes que precisam receber crescente atenção dos pesquisadores desta área.

Obviamente todos estes tópicos não são passíveis de serem tratados profundamente aqui. Desta feita, cumpre alertar que este artigo possui um caráter introdutório e exploratório de algumas das questões acima citadas. Busca-se nele apontar as caraterísticas e transformações mais gerais do mercado internacional de divisas, aventando algumas considerações e questões a serem investigadas mais profundamente em trabalhos futuros.

No presente artigo pretende-se delinear um caminho alternativo de interpretação ao fenômeno de especulação em mercados cambiais a partir da análise de aspectos ligados à microestrutura destes mercados, isto é, às estruturas de ordem física (volume transacionado, prazos dos contratos, número de negociadores, principais divisas e praças etc.), informacional (acessibilidade às condições nas quais as transações são fechadas) e de agenciamento de transações (tipos de operadores e formas de efetivação de negócios). O objetivo é apontar evidências e fatos estilizados que referendem a hipótese de que a instabilidade do mercado de moedas contemporâneo é a ele inerente, dada, ao menos em parte, a própria forma como está organizado. A tentativa é delinear possíveis implicações da expansão e internacionalização, entre outras transformações, deste mercado sobre a dinâmica cambial, em geral, e das condições de fomentação endógena de ataques especulativos, em particular. A percepção de que as paridades de câmbio dependem de decisões dos operadores atuantes no mercado de moedas e de que, por sua vez, a estrutura deste mercado define os espaços para a ação destes operadores conduziu alguns 
economistas a deixarem de tratar a taxa de câmbio como variável na qual preponderam somente os elementos macroeconômicos para a definição de sua dinâmica (por exemplo, FRANKEL; ROSE, 1996).

$\mathrm{Na}$ próxima seção, apresenta-se, de forma resumida, o desenvolvimento das interpretações teóricas de crises cambiais. A seguir, trata-se do volume de negócios do mercado cambial global nos mercados à vista e de derivativos, de algumas características das suas formas de transações e das transformações pelas quais vem passando. Mostra-se a evolução dos recursos transacionados nesses mercados e a de suas interrelações. Nas seções seguintes, são apresentadas informações sobre os mais destacados mercados de divisas, a internacionalização dos mercados nacionais de divisas, novos mecanismos de comercialização de moedas, principais operadores e os novos agentes/instituições nele envolvidos. Finalizando, apresentam-se os comentários finais.

\section{EVOLUÇÃO DO ARCABOUÇO TEÓRICO SOBRE CRISES CAMBIAIS}

Até os casos de crises cambiais em diversos países europeus, em 1992/1993, examinava-se e procurava-se explicar ataques especulativos à taxa de câmbio por meio de modelos nos quais a paridade cambial era definida a partir de uma relação linear com um conjunto definido de variáveis macroeconômicas - os chamados fundamentos cambiais. Tais modelos FLOOD e GARBER (1984a e 1984b), OBSTFELD (1984 e 1986), WYPLOSZ (1986), entre outros - derivaram-se do desenvolvido por Paul KRUGMAN (1979) - formaram a denominada interpretação ortodoxa tradicional para eventos de crises cambiais. Nela, os ataques especulativos contra certas moedas surgiam como uma reação racional dos agentes privados frente a uma política macroeconômica inconsistente no longo prazo: a autoridade econômica tenta combinar uma política de câmbio fixo com políticas fiscais-monetárias expansionistas, cujo resultado é a queda gradativa das reservas cambiais do país.

Com o fracasso desses modelos em prever e explicar as crises cambiais em alguns dos países membros do Sistema Monetário Europeu e nos países nórdicos, em 1992/1993, de imediato surgiu ampla literatura, inicialmente com conotação mais empírica (ver, por exemplo, EICHENGREEN; WYPLOSZ, 1993, ROSE; SVENSSON, 1994 e EICHENGREEN; ROSE; WYPLOSZ, 1994 e 1995), discutindo tais crises - 
OBSTFELD (1994, 1996), GERLACH e SMETS (1994) e OZKAN e SUTHERLAND (1995). As conclusões desses trabalhos, além de conduzirem ao questionamento das hipóteses presentes na interpretação ortodoxa tradicional, abriram espaços para o desenvolvimento de novas linhas teóricas. Com base na literatura de equilíbrio múltiplo da taxa de câmbio, formulada ao longo da década de 80 , mostrou-se como a definição do nível de equilíbrio da taxa de câmbio poderia depender das expectativas cambiais privadas prevalecentes no mercado. Dúvidas foram lançadas sobre a pressuposição de existência de uma relação estável entre a taxa de câmbio e os seus fundamentos macroeconômicos. Tanto empiricamente quanto teoricamente, mostrou-se que tal relação seria "intermediada" pelas instáveis expectativas privadas relacionadas à taxa de câmbio.

Ocorreu, portanto, uma mudança de perspectiva na análise sobre os efeitos dos movimentos especulativos no sistema econômico. Os movimentos especulativos deixaram de ser compreendidos como a mera (re)ação racional dos agentes privados, diante de circunstâncias gestadas por políticas contraditórias da autoridade econômica, e passaram a ser considerados eles mesmos os fomentadores de crises cambiais. Nesses termos, pressupõese a existência de "um elemento auto-realizável em crises de moeda que pode fazer mesmo taxas de câmbio tecnicamente sustentáveis politicamente difíceis de serem mantidas." (OBSTFELD; ROGOFF, 1995, p. 90)

Os pontos relativos à formação das expectativas cambiais começaram a ser explorados inclusive de sua relação nebulosa e não-linear com variáveis macroeconômicas. OBSTFELD (1996) lançou luz sobre a questão de interação entre os agentes privados e destes para com a autoridade econômica, no entendimento do fenômeno de ataque especulativo à taxa de câmbio. Valendo-se da Teoria dos Jogos, construiu "jogos" não-cooperativos em que apareciam dois agentes privados, para os quais os payoffs, envolvidos na decisão de especularem ou não com a paridade cambial, definir-se-iam de acordo com o montante de reservas cambiais possuídas pela autoridade econômica, terceiro partícipe do "jogo". Concluiu o autor que, mesmo a taxa de câmbio sendo sustentável na ausência de pressões especulativas, ela seria solapada se as expectativas fomentadoras destas pressões prevalecessem no mercado. "Nesse jogo, o ataque [correspondendo a uma trajetória de] equilíbrio tem um elemento auto-realizável porque a taxa de câmbio colapsa se atacada, mas sobrevive se isto não ocorrer" (OBSTFELD, 1996, p. 1041). Em algumas situações limites, os fundamentos seriam tais que tornariam a paridade cambial ou totalmente imune a ataques especulativos, ou completamente insustentável. Porém, na maioria dos casos concretos, os "fundamentos não são nem tão 
fortes, para fazer um ataque impossível, nem tão fracos, para fazer ele inevitável" (OBSTFELD, 1996, p. 1041). De fato, seria o comportamento conjunto dos agentes que atuam, ou venham a atuar, no mercado cambial que determinaria a sustentabilidade da paridade cambial.

Conclusões como essas impulsionaram trabalhos - DE GRAUWE e DECUPERE (1992), LYONS (1995), TAYLOR e ALLEN (1992), entre outros - que, de diversas formas, retiram o estudo da taxa de câmbio da esfera de variável determinada tão-somente por condicionantes macroeconômicos, imputando-lhe elementos mais diretamente ligados aos termos nos quais funcionam os mercados de moedas. Começou-se a dar importância aos aspectos concernentes às principais características dos mercados cambiais contemporâneos, destacando os fatores institucionais, organizacionais e operacionais, para a determinação da dinâmica da taxa de câmbio e do comportamento geral do mercado e dos investidores.

Tal linha de pesquisa teórica, denominada de microestrutura dos mercados cambiais, apesar de ainda incipiente, busca destacar a dimensão microeconômica da taxa de câmbio, ou seja, explicitar as particularidades da estrutura de comercialização subjacente aos mercados de moedas, para mais adequadamente apreender o seu comportamento e fenômenos relacionados.

\section{EVOLUÇÃO DO VOLUME E DAS FORMAS DE TRANSAÇÕES}

Com o fim do sistema de administração cambial que vigorava em Bretton Woods, no início da década de 70, e, consequentemente, das intervenções sistemáticas dos bancos centrais nos mercados de divisas com o objetivo de restringir as flutuações cambiais às estreitas bandas previamente definidas, os agentes privados deixaram de dispor de "balizas" para as suas expectativas cambiais, abrindo-se espaços para os operadores cambiais realizarem tanto ganhos de arbitragem quanto de especulação. ${ }^{1}$ As taxas de câmbio passaram a apresentar elevada volatilidade, uma vez que elas

1 No entanto, movimentos especulativos no mercado cambial não podiam ser considerados inteiramente como novidades. Mesmo antes do colapso de Bretton Woods, ocorreram diversos casos, em especial nos momentos finais deste sistema. Basta lembrar os casos de pressões depreciativas contra a libra esterlina, no final de 1967, e de pressões 
se transformaram em resultantes das várias decisões privadas de compra e venda e os especuladores, ao contrário do que previam as interpretações econômicas ortodoxas, à época influenciadas por FRIEDMAN (1953), não pautaram suas ações atentos a uma taxa de câmbio de equilíbrio de longo prazo (GOODHART, 1988). Isto refletia e estimulava a dispersão das expectativas quanto aos valores futuros das paridades cambiais, mesmo para períodos de curto prazo. O resultado foi o aumento das operações cambiais impulsionadas por expectativas de variações de paridades esperadas em um curtíssimo horizonte de tempo, isto é, transações que são efetuadas e, no decorrer do mesmo dia, desfeitas, via transações em sentido inverso - operações intradiárias (intraday).

O mercado cambial internacional foi conformando-se como um mercado global descentralizado - isto é, no qual não interfere nenhuma instituição central ajustando e organizando as operações -, que funciona, ininterruptamente, 24 horas por dia, com os operadores e negociadores de moedas seguindo o sol pelo globo, graças aos avanços das telecomunicações e da informática, redutores dos custos e do tempo das transações financeiras internacionais. Tendo como base o horário GMT (Greenwich Mean Time), atualmente a semana de negócios em tal mercado começa às $22 \mathrm{~h} 30 \mathrm{~min}$ do sábado, com a abertura das operações cambiais nas praças de Tóquio e de Sidney (Austrália), e termina às 22h30min da sextafeira, com o fechamento das operações dos mercados da Costa Oeste dos EUA. $^{2,3}$

No início da década de oitenta, o volume diário de transações nos mercados cambiais já estava em torno de US\$ 100 bilhões (GRABBE, 1996, p. 27). Mas foi apenas a partir de 1989, quando o Bank International

apreciativas contra o marco alemão, em abril de 1971, quando o banco central alemão, Bundesbank, em apenas um único dia, precisou intervir no mercado cambial comprando US\$ 3 bilhões da divisa norte-americana, a fim de sustentar a paridade dólar/marco (GRABBE, 1996, p. 24). O que diferenciou a especulação após Bretton Woods foi o seu caráter rotineiro.

2 Enquanto se mantém aberta a semana de negócios, contínuos fluxos de capitais cruzam, através das redes de telecomunicação, as fronteiras de diferentes países, buscando sempre atuar nos mercados cambiais em funcionamento, guiados pela difusão instantânea de informações referentes às cotações.

3 Em um fenômeno ainda intrigante aos estudiosos sobre o tema, quando os mercados de Nova Iorque e europeus estão simultaneamente em operação, nota-se, com recorrência, em tais mercados, a ascensão do volume de negócios (Federal Reserve Bank of New York - FRBNY, 1995, p. 8) e da volatilidade das paridades de câmbio (FRANKEL; FROOT, 1990) a patamares superiores àqueles verificados nos demais momentos do dia. 
Settlements (BIS), em conjunto com diversos bancos centrais, ${ }^{4}$ começou a estimálo sistematicamente que se passou a dispor de dados mais confiáveis sobre a evolução deste mercado. Entre 1989 e 1998, verificou-se um crescimento de 156\%. Apenas de 1992 a 1995, o mercado global de moedas expandiu-se à taxa de $45 \%$, ou seja, cerca de $13 \%$ ao ano em média. Nos três anos seguintes, em parte devido ao processo de lançamento da moeda única na Europa, em parte decorrente da crise asiática no segundo semestre de 1997, ocorreu uma desaceleração, com os negócios crescendo "apenas" 26\% no período. Em abril de 1998, o giro médio diário estimado de negócios com trocas de divisas no mercado global alcançou o valor líquido, i. e., já descontada a dupla contagem, de US \$ 1,59 trilhão. Tal pesquisa confirmou a posição do mercado de divisas como o maior mercado financeiro da atualidade, tomando como critério o valor do giro médio diário de negócios. ${ }^{5}$

Embora esses índices de expansão dos anos 90 sejam inferiores às estimativas de crescimento para a década de 80 , quando o volume estimado de negócios cresceu à taxa média de $20 \%$ ao ano, ${ }^{6}$ ainda são bastante superiores, por exemplo, às taxas de crescimento do comércio internacional. ${ }^{7}$ Isso denota a crescente importância dos fluxos financeiros e especulativos sobre os mercados de moedas, engendrando o fenômeno de financeirização das taxas de câmbio.

4 Em 1995, a pesquisa cobriu 26 países: África do Sul, Alemanha, Austrália, Áustria, Barein, Bélgica, Canadá, Singapura, Dinamarca, Espanha, Estados Unidos, Finlândia, França, Grécia, Holanda, Hong Kong, Irlanda, Itália, Japão, Luxemburgo, Noruega, Nova Zelândia, Portugal, Reino Unido, Suécia, Suíça. No último levantamento do BIS, feito em abril de 1998, incorporaram-se mais 17 países: Argentina, Brasil, Chile, China, Córeia do Sul, Hungria, Índia, Indonésia, Malásia, México, Filipinas, Polônia, República Checa, Rússia, Arábia Saudita, Taiwan e Tailândia. Juntos, os negócios cambiais destes 17 países totalizaram US\$ 42,1 bilhões.

5 Nos EUA, o segundo maior mercado, o de títulos governamentais, apresentava, em abril de 1995, um giro médio diário de US\$ 175 bilhões, valor inferior ao estimado para o mercado de câmbio naquela mesma data, US\$ 244 bilhões (FRBNY, 1995).

6 CANUTO e LAPLANE indicam que a taxa média de crescimento dos negócios cambiais, na década de 80 , foi de $30 \%$ a. a.

7 Em 1995, por exemplo, o valor anual das trocas internacionais de bens e serviços alcançou a cifra de US\$ 4,3 trilhões, isto é, o equivalente, aproximadamente, apenas a 3 dias e meio de negócios no mercado cambial global na época. 
Tabela 1 - GIRO MÉDIO DIÁRIO LÍQUIDO ESTIMADO DO MERCADO DE MOEDAS

em US\$ bilhões

\begin{tabular}{lrrrrr}
\hline \multicolumn{1}{c}{ TRANSAÇÕES } & ABRIL/1989 & ABRIL/1992 & ABRIL/1995 & ABRIL/1998 \\
\hline À vista & 350 & 400 & 520 & 590 \\
A termo e swaps & 240 & 420 & 670 & 900 \\
Futuros e opções & 30 & 60 & 45 & 97 \\
TOTAL & 620 & 880 & 1235 & 1587 \\
\hline
\end{tabular}

FONTES: BIS (1996a) e BIS (1998).

Reforça-se essa conclusão quando se observa que grande parte desse crescimento recente no mercado global de moedas representa a contraparte do aumento das operações cambiais intradiárias (intraday). Crescente número de negociadores de moedas, principalmente os bancos atuantes como market makers, ${ }^{8}$ passou a assumir posições compradas de certas moedas, baseado na expectativa de que estas terão, no decorrer ou em algum momento do dia, uma apreciação capaz de lhe propiciar ganhos com a revenda das mesmas. Passadas algumas horas ou aproximando-se o horário de fechamento do mercado, estes negociadores, mesmo sem verem sancionadas suas expectativas, desfazem-se das suas posições cambiais para não terem que carregá-las de um dia para outro e, dessa forma, correrem riscos cambiais desnecessários.

É aceitável supor que essas formas de operações intradiárias pouco estão ligadas a fluxos de comércio e serviços - conforme o BIS (1996a), menos de $20 \%$ das transações envolvem, em uma das pontas, agentes nãofinanceiros - e a fluxos tradicionais de capital. Como enunciado acima, o mais provável é que se originam, impulsionam-se e realizam seus ganhos ou perdas a partir da própria, e relativamente autônoma, dinâmica contemporânea dos mercados cambiais, nos quais as paridades entre as principais moedas apresentam incessante variabilidade de curtíssimo prazo. Na década de 90, tais tipos de transação passaram a representar $90 \%$ das trocas de divisas: "Uma instituição chega a efetuar entre 3-4 mil operações num dia normal de 24 horas e cerca de $50 \%$ mais do que isso num dia turbulento. [...] Nos períodos mais agitados, um único dealer chega a efetuar uma operação a cada 3-4 minutos." (ITO et al., 1996, p. 121-122)

8 De fato, da década de 70 para hoje, ampliaram-se muito os negócios dos bancos com divisas. Por exemplo, conforme FIELEKE (1981, p. 37), em 1978, a parcela de posições dos bancos americanos em ativos estrangeiros não ultrapassava $1 \%$ dos ativos totais. Reconhecia-se, então, que dificilmente as posições em divisas desses bancos fossem capazes de influenciar as paridades cambiais. 
Portanto, essa forma de atuar nos mercados de divisas, que prioriza os movimentos de curtíssimo prazo, pode ser entendida como uma das conseqüências, mas, simultaneamente, uma das causas da volatilidade cambial que se instalou nos mercados de moeda desde o fim de Bretton Woods: "As cotações podem mudar 20 vezes no espaço de um minuto, no caso das principais moedas, com a taxa dólar-marco alemão mudando até 18 mil vezes num único dia" (ITO; FOLKERTS-LANDAU et al., 1996, p. 122). Como tais variações de cotações são rapidamente disponibilizadas para um grande número de operadores de diversas partes do mundo, graças aos sistemas eletrônicos de distribuição de informações financeiras (Reuters, Telerate etc.), elas podem, em determinadas circunstâncias - se representarem, por exemplo, uma frustração nas expectativas dominantes nos mercados -, disparar instantânea e abrupta reação simultânea dos aplicadores, muitas vezes feitas via sistemas automáticos de comercialização de moedas (ver KRUGMAN; MILLER, 1993). Tornam-se, assim, capazes de engendrar novas rodadas de variações das cotações, após terem sido processadas em um sistema de complexa interatividade entre os principais agentes atuantes nestes mercados, fundamentalmente os dealers, cujos negócios entre si representam $64 \%$ do volume total transacionado (BIS, 1996a). ${ }^{9}$ Assim, um crescente número de agentes terminou por perceber a possibilidade de se poder obter bons ganhos financeiros prevendo os movimentos futuros das paridades cambiais, sem que, para isso, se necessitasse ficar muito tempo de posse de uma divisa, pois esses movimentos dar-se-iam em curtos intervalos de tempo, muitos abrangendo espaços de poucas horas ou mesmo de minutos. Como lembra um dos mais importantes "jogadores" desse mercado, o banco alemão Deutsche Bank, "volatilidade é [...] a palavra que melhor descreve os mercados financeiros desenvolvidos, particularmente o mercado cambial, nos últimos tempos." (EUROMONEY RESEARCH GUIDES. The 1996 Guide to London. Dec. 1995, p. 14).

Nesse sentido, o próprio mercado cambial tornou-se um locus de valorização do capital, um espaço para operações especulativas, com as moedas transformando-se em uma classe especial de ativos financeiros e, cada vez mais, tomando parte das carteiras dos investidores internacionais. (COUTINHO; BELLUZZO, 1996, p. 136)

9 Dealers são os agentes que atuam no mercado de moedas (como em outros mercados monetário-financeiros) fornecendo as cotações de compra e venda, mantendo um estoque próprio de moedas em carteira para atender às solicitações de compra ou venda de moedas sempre que estas ocorrerem. Cumprem, assim, a função de market makers do mercado cambial. Constituem-se, basicamente, de instituições bancárias. 
Simultânea e gradativamente, tal autonomia das variações cambiais diante dos fundamentos macroeconômicos implicou e estimulou um caráter cada vez mais autocentrado dos operadores cambiais, isto é, os mercados cambiais tornaram-se crescentemente auto-referenciais, de tal forma que os prognósticos cambiais dos participantes dos mercados não representam apenas antecipações das taxas futuras, como também passaram a ser determinantes para a formação de tais taxas (HARVEY; QUINN, 1997, p. 616). Isto pode ser claramente observado por meio das mudanças nos instrumentos e estratégias de construção de prognósticos cambiais utilizados pelos operadores atuantes nestes mercados. Os modelos apoiados sobre avaliações dos fundamentos foram perdendo importância na montagem de modelos de previsão para horizontes de tempo de curto prazo. Em contrapartida, disseminaram-se os modelos de "análises técnicas", que providenciam prognósticos de cotações a partir da análise visual do comportamento passado dos movimentos das paridades cambiais, desconsiderando os fundamentos cambiais da análise. Consiste-se, portanto, de tentativas de identificação de padrões comportamentais dos movimentos cambiais capazes de orientar as previsões referentes às variações de curto prazo das paridades. Uma das formas mais comuns de análise técnica é a denominada análise grafista, que consiste em expressar graficamente as cotações passadas de determinada paridade cambial com o intuito de identificar seqüências de "picos" e "vales" passíveis de repetirem-se no futuro. Portanto, tais técnicas dão um caráter eminentemente extrapolativo às expectativas cambiais.

Dados levantados anualmente pela revista britânica Euromoney, entre 1978 e 1988, junto a diversas empresas fornecedoras de serviços de prognósticos cambiais, evidenciam a tendência de utilização crescente de modelos técnicos pelos operadores cambiais (FRANKEL; FROOT, 1990). Em 1978, das vinte e duas empresas consultadas, apenas duas afirmaram usar somente modelos técnicos para a construção de seus prognósticos e uma disse usar tanto modelos técnicos quanto "fundamentalistas". As demais se utilizavam apenas de modelos "fundamentalistas", isto é, baseavam seus prognósticos sobre avaliações dos fundamentos cambiais. Todavia, em 1988, enquanto doze empresas, de uma amostra de vinte e sete, declaram usar apenas modelos técnicos, apenas uma afirmou lastrear seus vaticínios unicamente sobre modelos "fundamentalistas". Dados apresentados por TAYLOR e ALLEN (1992) reforçam a importância que os modelos de análise técnica passaram a ter para os agentes atuantes nos mercados de divisas. Conforme pesquisa realizada, em novembro de1988, pelos autores junto a 213 instituições operantes em Londres, $90 \%$ delas utilizavam-se de algum tipo de análise técnica para a formulação de suas expectativas cambiais referentes a períodos de 
curto prazo. Ainda segundo estes autores, algumas respostas fornecidas pelas instituições pesquisadas fornecem evidências de que o uso disseminado de análises técnicas pelos operadores cambiais fomenta fenômenos de "efeito manada" (TAYLOR; ALLEN, 1992, p. 110).

\section{SISTEMAS DE CORRETAGEM ELETRÔNICA (ELECTRONICS BROKERS)}

Apesar de restringir-se, por enquanto, aos negócios à vista e envolverem tão-somente as paridades cambiais mais transacionadas, a introdução de sistemas eletrônicos de corretagem de divisas (electronics brokers) constitui uma das principais inovações ocorridas em mercados cambiais, nos últimos anos. Através deles, os agentes podem verificar as cotações de compra e venda das principais moedas e as quantidades ofertadas e demandadas a estes preços, bem como efetivar as transações cambiais à paridade vigente no momento, por meio de terminais de computadores conectados ao sistema eletrônico de corretagem. Para acessá-los, os operadores cambiais dispõem de senhas e pagam por transações efetuadas - no Electronic Broking Service (EBS), sistema patrocinado pelo Citibank, por exemplo, cada transação custa US\$25,00, independentemente do seu valor. Em Londres existem dois sistemas eletrônicos de corretagem de moedas - EBS e Reuters Dealing 2000-1, os quais foram responsáveis por cerca de $11 \%$ dos negócios em abril de 1998 (Bank of England, 1998). Em Nova Iorque, 13\% dos negócios de câmbio e $32 \%$ das operações à vista foram realizados através desses sistemas em abril de 1998 (FRBNY, 1998).

A introdução e a disseminação de sistemas de corretagem eletrônica são mais alguns dos elementos a intensificar a integração dos diversos mercados cambiais nacionais e a ampliar aos agentes os canais de acesso aos mercados internacionais. Esses sistemas permitem que o mercado de câmbio no qual eles se localizam possa ser acessado por agentes de diferentes partes do mundo em tempo real e a reduzidos custos. Assim, por exemplo, agentes fora de Londres, sejam bancos tailandeses, sejam fundos de pensão brasileiros, podem efetivar transações cambiais no interior do mercado cambial londrino, desde que estejam conectados a um dos sistemas de corretagem eletrônica nele existente. O Dealing 2000-2 e o EBS já têm, respectivamente, mais de 4.500 e 1.500 terminais espalhados pelo mundo. 
Uma das consequiências desses sistemas eletrônicos de cotação é a maior disponibilidade de informações para os agentes dispostos a realizarem operações cambiais. Graças a eles, os compradores finais de moedas conseguem perceber mais fácil e rapidamente a situação do mercado e, portanto, realizar seus negócios em melhores condições. Permitem também que pequenos operadores, sejam bancos ou outras instituições financeiras nãobancárias, possam negociar diretamente entre si, sem a intermediação de corretoras tradicionais ou de grandes bancos (Euromoney, July 1996, p. 155).

De fato, os sistemas de corretagem eletrônica vêm sendo usados principalmente pelos operadores de menor porte, fazendo com que neles predominem transações de valor relativamente pequeno. Porém, nos últimos anos, grandes bancos de investimento - JP Morgan, Merril Lynch - também começaram a servir-se desses sistemas para efetuarem seus negócios com divisas, pois, em períodos de normalidade, tais sistemas já são capazes de realizar operações de até US\$ 200 milhões. Não obstante, em períodos de apreensão e de incerteza, nos quais os movimentos especulativos dominam de maneira mais intensa o mercado de câmbio, esses sistemas perdem, de forma abrupta, liquidez, a ponto de o sistema ter que parar de operar e os negócios precisarem ser deslocados para o interbancário.

A possibilidade de os pequenos e médios agentes, em especial bancos com atuação regional, conseguirem negociar com divisas sem precisarem, em simultâneo, fornecer cotações de compra-venda - isto é, tornarem-se agentes price takers dentro do mercado de divisas - , juntamente com o maior acesso a informações que os sistemas eletrônicos de comercialização eletrônica de divisas lhes proporcionam, vem tendo suas conseqüências sobre a rotina do mercado cambial. Os market makers queixamse de que a introdução dos sistemas de corretagem eletrônica provocou redução das comissões, dos spreads de compra-venda e, consequentemente, das taxas de lucros originadas das atividades e serviços realizados nos mercados de moedas. No mesmo sentido, um número cada vez menor de instituições, em sua maioria os grandes bancos globais, tornou-se responsável pelos serviços de cotação de moedas e de operacionalização de transações com montantes mais significativos em razão de bancos e outras instituições de menor porte deixarem de fornecer rotineiramente cotações de divisas ao mercado.

Essa concentração das funções de fornecimento das cotações cambiais pode não ser muito benéfica à estabilidade do mercado de divisas. Afinal, apesar dos crescentes volumes de recursos a circularem nesse mercado, é possível a ocorrência de uma queda na liquidez dos mesmos, em especial no segmento interbancário, uma vez que se reduziu o número de agentes atuando, de forma rotineira, como market makers, em virtude da 
introdução dos sistemas de corretagem eletrônica. Nas palavras do chefe do setor de câmbio de um grande banco internacional, a "corretagem eletrônica tem removido os operadores menores do mercado, que atuavam como lubrificantes do mercado de câmbio. Isso significa que os grandes bancos tornaram-se mais capazes de mover o mercado" (Euromoney, July 1996, p. 155). Agora, os agentes de menor porte apenas "tomam liquidez" do mercado, mas não a providenciam. Isso pode também significar a redução da capacidade dos mercados cambiais de absorver choques exógenos ou vieses de interpretação quanto às condições objetivas da economia, em virtude da concentração dos negócios nas mãos de poucos bancos.

É difícil, por enquanto, ter uma posição definida quanto às conseqüências efetivas desses sistemas para as condições de formação de movimentos especulativos em mercados de câmbio. Todavia, por reduzirem as possibilidades de ganhos com a execução de negócios cambiais tidos como tradicionais - serviços de compra e venda à vista de moedas -, nos mercados mais desenvolvidos, existem indícios de que os sistemas de corretagem eletrônica têm impelido os grandes operadores privados de divisas a não apenas atuarem de forma mais agressiva na oferta de outros "serviços" cambiais, como também a darem mais atenção aos mercados cambiais dos países considerados emergentes. Isso pode significar tanto maior disposição para atividades especulativas quanto maiores questionamentos sobre os "corretos" valores relativos internacionais das moedas desses países.

\section{PRINCIPAIS CENTROS CAMBIAIS E MOEDAS NEGOCIADAS}

Apesar da expansão do volume de recursos circulantes no mercado de divisas global, as transações ainda continuam a concentrar-se em poucas praças financeiras. Em abril de 1998, as três principais praças responsabilizaram-se por 58\% das transações - Londres, US\$ 637 bilhões; Nova Iorque, US\$ 351 bilhões; e Tóquio, US\$ 148 bilhões. Entre estas, destaca-se Londres, que nos últimos anos vem acentuando a sua posição de mais importante e internacionalizado mercado cambial do planeta. Entre 1992 e 1998, sua participação no volume global de negócios cambiais passou de $27 \%$ para $32 \%$.

Apesar da expansão das operações em mercados cambiais dos países chamados emergentes, os principais mercados - Londres e Nova Iorque 
continuarão a concentrar os negócios com moedas, até porque neles se verifica a contraparte mais sofisticada, em termos de instrumentos derivativos, das transações realizadas nos mercados emergentes, $i$. e., as operações de derivativos com a finalidade ou de proteger as aplicações de capital feitas nestes mercados por investidores internacionais de variações acentuadas nas taxas de câmbio pertinentes, ou de instrumentalizar posições especulativas contra as moedas desses países.

Tabela 2 - VOLUMES MÉDIOS DIÁRIOS DE TRANSAÇÕES NOS PRINCIPAIS MERCADOS DE CÂMBIO

em US\$ bilhões

\begin{tabular}{lrrrrr}
\hline \multicolumn{1}{c}{ PAÍSES } & ABRIL/1989 & ABRIL/1992 & ABRIL/1995 & ABRIL/1998 \\
\hline Reino Unido & 184 & 290 & 464 & 637 \\
Estados Unidos & 115 & 167 & 244 & 351 \\
Japão & 111 & 120 & 161 & 149 \\
Singapura & 55 & 74 & 105 & 139 \\
Hong Kong & 49 & 60 & 90 & 79 \\
Suíça & 56 & 66 & 87 & 82 \\
Alemanha & $\ldots$ & 55 & 76 & 94 \\
Outros (a) & $148(\mathrm{~b})$ & 244 & 344 & 440 (c) \\
TOTAL (d) & 718 & 1076 & 1571 & 1971 \\
\hline
\end{tabular}

FONTES: BIS (1996a) e BIS (1998).

NOTAS: (a) Inclui África do Sul, Alemanha, Austrália, Áustria, Barein, Bélgica, Canadá, Dinamarca, Espanha, Finlândia, França, Grécia, Holanda, Irlanda, Itália, Luxemburgo, Nova Zelândia, Noruega, Portugal e Suécia.

(b) Somente Canadá.

(c) Inclui os países citados em (a) mais os 17 novos países relacionados na nota de rodapé número 3.

(d) Os valores são líquidos, mas com dupla contagem nas transações entre dealers de um mesmo território.

Há concentração também no que se refere às moedas transacionadas no mercado cambial global. O dólar americano e o marco alemão estão envolvidos em $87 \%$ e $30 \%$, respectivamente, das transações cambias globais. ${ }^{10}$ Segundo o BIS (1996a), das dez paridades mais negociadas,

10 Esclarece-se ao leitor que, como cada operação cambial envolve duas moedas, a percentagem máxima que uma única moeda pode estar envolvida na totalidade de operações é de $100 \%$, ou seja, tal moeda sendo trocada com todas as demais, e estas somente com ela. Porém, a soma total das percentagens de participação de todas as moedas perfaz $200 \%$. 
sete têm a moeda americana em uma das pontas, e quatro a moeda alemã, com o primeiro lugar cabendo, justamente, à paridade dólar/marco, com 22\% das transações totais. Trata-se, com significativa vantagem para o dólar, das únicas moedas que são "comercializadas, em grande quantidade, junto a um amplo número de outras moedas" (BIS, 1996a, p. 8) e, portanto, que podem ser consideradas moedas internacionais. O dólar americano pode mesmo ser considerado uma espécie de "moeda veículo", com a qual os agentes transitam de uma moeda para a outra via operações cambiais cruzadas. ${ }^{11}$ Mesmo em Tóquio, segundo dados do Banco do Japão, o envolvimento do dólar (91,8\%) nas transações cambiais mostrou-se, em 1998, superior ao do iene $(83,5 \%)$, pois muitas operações de troca entre moedas asiáticas tomam como "ponte" o dólar em vez do iene.

Tabela 3 - PARTICIPAÇÃO DAS PRINCIPAIS MOEDAS NAS TRANSAÇÕES CAMBIAIS

em $\%$

\begin{tabular}{lr|r|r|r}
\hline \multicolumn{1}{c}{ MOEDA } & ABRIL/1989 & ABRIL/1992 & ABRIL/1995 & ABRIL/1998 \\
\hline Dólar americano & 90 & 82 & 83 & 87 \\
Marco alemão & 27 & 40 & 37 & 30 \\
Iene & 27 & 23 & 24 & 21 \\
Libra esterlina & 15 & 14 & 10 & 11 \\
Franco francês & 2 & 4 & 8 & 5 \\
Franco Suíço & 10 & 9 & 7 & 7 \\
Outras & 29 & 28 & 31 & 39 \\
TOTAL & 200 & 200 & 200 & 200 \\
\hline
\end{tabular}

FONTE: BIS (1998).

Embora não aprofundando aqui essa questão, assume-se a idéia de AGLIETTA (1986) quanto à existência de uma hierarquia entre as moedas no Sistema Monetário Internacional. O dólar e o marco (agora o euro) - cada qual na sua zona de influência - atuam como verdadeiras "âncoras" do mercado cambial global, pois não apenas servem de referência às expectativas dos

11 Isto é, utiliza-se o dólar como forma de realizar uma transação envolvendo uma paridade cambial que possua um mercado pouco líquido ou mesmo inexistente: um agente disposto a trocar a moeda A pela moeda B, primeiro troca a moeda A por dólar e, em seguida, utiliza-o para adquirir a moeda B. 
agentes, como também são as moedas às quais estes tendem a recorrer nos momentos de perturbações, desconfianças e incertezas com relação às moedas de "segunda linha". ${ }^{12}$ Nesse sentido, ataques especulativos à taxa de câmbio, em geral, envolvem uma corrida em direção a uma destas duas divisas.

\section{INTERNACIONALIZAÇÃO DOS MERCADOS CAMBIAIS}

Além da expansão do volume de recursos monetários que circulam nos mercados cambiais, observa-se também o crescente entrelaçamento e internacionalização dos vários mercados nacionais, formando o que se pode chamar, nos termos de ROMO (1997, p. 871), de um mercado global que transcende às restrições de cada mercado nacional. Conforme o BIS (1998), 54\% das transações cambiais, realizadas em abril de 1998, referiram-se a transações interfronteiras, i. e., envolviam agentes de países distintos. Outro número a expressar o crescimento desta internacionalização é o referente à participação das moedas domésticas sobre as transações cambiais totais de cada país. Enquanto em abril de 1992 47\% das transações envolviam a moeda nacional, em abril de 1995 este número caiu para 44\% (BIS, 1996b). Todavia, cabe ressaltar que os mercados cambiais nacionais, apesar de serem considerados, em distintos graus, subconjuntos do mercado global, ainda apresentam diferentes níveis de internacionalização/globalização. Seguindo dados do BIS (1996a), pode-se dividir os mercados cambiais domésticos em três categorias: 1) os internacionalizados; 2) os híbridos; e 3) os fechados. No primeiro grupo, situam-se as praças de câmbio de Singapura, Luxemburgo, Londres e Hong Kong, nas quais as respectivas moedas domésticas participam em menos de $20 \%$ das transações. Mercados cambiais com essa característica expressam a importância que as operações de especulação e de proteção têm sobre o volume total negociado, imprimindo nesses mercados uma dimensão eminentemente financeira. Já os mercados de câmbio norte-americano, alemão e japonês podem ser classificados como híbridos, uma vez que as respectivas

12 De fato, mesmo as três principais moedas do Sistema Monetário Internacional podem sofrer surtos de desconfianças por parte dos investidores internacionais. Observa-se que isso aconteceu com o marco alemão e o iene, cada qual por motivos distintos, no período recente de 1996-1997. Nesse caso, a terceira moeda da tríade, o dólar, e os ativos financeiros nele denominados acabaram servindo de "porto seguro" aos investidores internacionais (FOLKERTS-LANDAU et al., 1997). 
moedas domésticas partilham, de forma quase igual, com as estrangeiras o envolvimento nas transações cambiais. O papel simultâneo de moeda de referência nas transações financeiras e econômicas internacionais cumprido pelas moedas desses países e a importância mundial e/ou regional de cada um desses mercados cambiais explica tal divisão. No terceiro grupo, as moedas domésticas estão envolvidas em mais de $50 \%$ das transações, significando que, neles, as transações cambiais originam-se, majoritariamente, de operações comerciais ou financeiras não-especulativas. África do Sul, Canadá, Espanha e Portugal são exemplos de países que possuem mercados cambiais que podemos classificar como "fechados".

Tanto o crescimento de recursos quanto a internacionalização verificada no mercado cambial mundial, nos últimos anos, espelham a desregulamentação e a abertura externa (liberalização) dos diversos mercados financeiros nacionais ${ }^{13}$ - acionário, de títulos privados, de títulos públicos (GOLDSTEIN et al., 1993 e BURNHAM, 1991). O desenvolvimento de novos instrumentos financeiros e de técnicas de comercialização e de administração dos riscos e retornos envolvidos em cada ativo também corroboram para esse crescimento ao permitirem aos agentes dispostos a empreenderem transações interfronteiras e baixos custos de transação, monitoração e proteção. Nestas novas circunstâncias, os administradores de carteiras e os investidores institucionais sentem-se estimulados a diversificar cada vez mais suas aplicações em direção a ativos estrangeiros (FRANKEL; ROSE, 1996).

Embora não se possa estabelecer ainda uma relação segura de causa-efeito, estudos apontam para a existência de correlação positiva entre a volatilidade cambial e o volume de recursos transacionados nos mercados de moedas. ${ }^{14}$ Entre outras evidências nesse sentido, nota-se que os momentos do dia nos quais diferentes mercados nacionais de câmbio operam simultaneamente são aqueles em que, de maneira geral, apresentam-se as oscilações

13 A “explosão nos volumes de transações cambiais foi a contraface da operação do sistema financeiro global permitido pela liberalização" (CANUTO; LAPLANE, 1995, p. 31). Porém, a expansão dos negócios cambiais está também ligada à redução do horizonte de "aplicação do capital" nestes mercados, fruto da sua transformação em locus de valorização de riqueza, por meio da exploração da volatilidade diária das paridades.

14 FRANKEL e FROOT (1990), ITO (1990), FRANKEL (1993), JORION (1996) e HSIEH e KLEIDON (1996) encontraram correlação positiva entre o volume de transações no mercado cambial e a volatilidade da taxa de câmbio. Parece também, conforme mostram estas análises, que o crescimento do número de agentes operando nos mercados cambiais é acompanhado de aumento no grau de heterogeneidade das expectativas. 
mais fortes nos valores relativos entre as moedas. Há a possibilidade de isso indicar momentos nos quais, pelo fato de os mercados de moedas se apresentarem mais "internacionalizados", os agentes estrangeiros ingressantes no mercado procurem efetivar o maior número possível de transações, com o intuito de melhor perceberem o mercado e, com isso, eliminarem eventuais desvantagens informacionais que tenham em relação aos agentes domésticos.

\section{DERIVATIVOS}

A expansão dos mercados de divisas também é explicada pela introdução e ampliação, desde o início da década de 80 (ver SHASTRI et al., 1996), das várias formas de derivativos cambiais - futuros, opções, swaps e forwards. Introduzidos no fim da década de 70 e início da de 80 , com o objetivo inicial de atender à demanda por instrumentos de proteção frente à incessante variabilidade das taxas de câmbio e, portanto, de facilitadores da administração de carteiras plurimonetárias, os derivativos passaram, rapidamente, a ser utilizados como instrumentos para o exercício de especulação com divisas. ${ }^{15}$ Não é exagero afirmar que eles se constituem na mais significante inovação do mercado de moedas nos últimos anos (GOLDSTEIN et al., 1993, p. 4). No ano de 1989, as operações com derivativos respondiam por 45\% dos negócios diários; em 1998, passaram a representar 60\%.

A inversão de posição entre mercado à vista e mercados de derivativos implica e reflete importantes alterações na própria dinâmica do mercado cambial. Com os derivativos, os agentes propensos a assumirem posições especulativas contra uma moeda necessitam dispor de muito menos recursos próprios, devido aos altos graus de alavancagem - efetivação de aplicações financeiras com baixo grau de comprometimento ex ante de capital próprio, isto é, opera-se no mercado com alto grau de recursos tomados em empréstimo - que os derivativos permitem. Isso, potencialmente, torna a presença dos agentes com menor aversão a riscos mais significante na definição da dinâmica dos mercados. No limite, tais agentes são capazes de pressionar o mercado na direção favorável às suas expectativas, sem necessitarem

15 FIELEKE (1981, p. 37-38), por meio da análise das posições em divisas de bancos e empresas americanas, no ano de 1980, conclui que, desde suas primeiras formas, os derivativos cambiais foram usados mais como meio adicional de investimento em moeda externa do que como mecanismo de proteção. 
despender significantes quantias de recursos próprios. O custo ex ante das apostas fica menor, tornando movimentos especulativos contra determinadas moedas mais atrativas, mesmo que não sustentados em desequilíbrios graves nos fundamentos cambiais, mas no objetivo de "testar" a capacidade e a determinação do governo em defender a política cambial vigente.

Entre os mercados de derivativos de moedas, o que vem apresentado maior dinamismo é o de swaps de moedas e de taxa de câmbio - $85 \%$ dos negócios com derivativos cambiais em abril de 1995 (BIS, 1996a). ${ }^{16}$ Por prestarem serviços com futuros de moedas, os bancos são os grandes usuários de swaps cambiais. Quando vendem um contrato de futuro ou de opções para um cliente - seja um investidor institucional, fundo de hedge, ou tesouraria de corporações industriais ou comerciais ${ }^{17}$-, eles procuram realizar, em simultâneo, a compra de swaps nas moedas e nos valores envolvidos no contrato futuro realizado com o cliente. Isso lhes permite evitar "posições descobertas" em uma moeda - ou seja, um compromisso futuro de pagamento nesta (ou entrega desta) divisa sem tê-la, no presente, em caixa -, "sobrecompradas" em outra - compromisso de, em data futura, comprá-la ou recebê-la -, e problemas de liquidez em seus caixas (ver GOODHART, 1988; KREGEL, 1994).

Tem-se por acordo que a expansão dos negócios de swaps cambiais reflete "a crescente sofisticação na administração da liquidez e do risco moeda por parte dos investidores" (BIS, 1996a, p. 19), acompanhada da desregulamentação e da abertura dos mercados financeiros nacionais. Como as operações de swaps necessitam de mercados altamente líquidos, os negócios com esta forma de derivativos estão, cada vez mais, concentrando-se nas grandes praças financeiras - entre abril de 1992 e abril de 1995, o giro médio diário de swaps de taxa de câmbio cresceu 99\% no Reino Unido. Uma das possíveis conseqüências disso é a imposição de maiores dificuldades para os bancos centrais monitorarem as posições e as expectativas privadas referentes à paridade de sua moeda com alguma das moedas "fortes" do sistema monetário internacional (ver GARBER, 1998). Embora sinalize a crescente sofisticação e complexidade das

16 A "operação de swap cambial" caracteriza-se pelo estabelecimento de um contrato de trocas de moedas (ou taxas de câmbio), em quantia e data específicas, com acordo de ser revertida, na mesma quantidade e com taxa de câmbio previamente determinada, em data futura, definida pelos agentes contratantes da operação.

17 Levantamento feito, em 1995, pela Greenwich Associates, empresa inglesa de consultoria e pesquisa, indicou que $55 \%$ das grandes empresas européias já tinham feito uso, até aquele ano, de alguma forma de instrumentos de opções cambiais. 
operações cambiais, é difícil definir com precisão e a priori que motivos estão por trás desse aumento dos recursos transacionados com derivativos cambiais. Dado o duplo caráter dos derivativos, podem estar preponderando tanto motivos especulativos quanto motivos ligados à necessidade de proteção (hedge) frente a riscos oriundos da própria internacionalização dos negócios comerciais e financeiros. Há também a maior determinação dos próprios bancos em fornecerem esse tipo de "produto financeiro" aos seus clientes. Como exposto, dada a redução das receitas auferidas com os negócios de câmbio no mercado à vista, os bancos têm procurado atuar mais agressivamente nas operações com derivativos cambiais, que podem lhes propiciar melhores ganhos. O responsável global pelos negócios cambiais do banco alemão Deutsche Bank, segundo maior operador mundial e primeiro nas transações dólar/marco em 1998, explicita essa posição:

Estamos alterando radicalmente [nossos negócios cambiais] em direção aos derivativos. Uma das mais claras tendências que temos identificado é que nossas operações com derivativos são a locomotiva dos nossos "spot desk" [escritórios de câmbio]. (Euromoney, May 1997, p. 64)

Entretanto, o fato de predominarem nos derivativos cambiais, principalmente nos de swaps de taxa de câmbio, contratos com prazo menor que um ano $-79 \%$ dos contratos, segundo estimativa feita pelo BIS, em março de 1995 -, indica que muitos deles talvez estejam mais ligados à tomada de posições especulativas de curto prazo em mercado de moedas do que a operações financeiras de longo curso, ligadas a aplicações de capital com maiores períodos de realização. Mesmo em condições nas quais a efetivação de contratos com derivativos espelhe uma operação de finalidade exclusiva de proteção contra riscos cambiais, estes instrumentos ainda podem significar instabilidade no mercado se se tratarem de hedges dinâmicos, como mostraram GARBER e SPENCER (1995).

\section{OPERADORES}

Embora ainda predominem, com $63 \%$ das transações totais com moedas sendo feita entre eles, os market makers viram sua participação diminuir seis pontos percentuais de 1992 a 1998. Apesar disso, os bancos com 
atuação global são ainda os agentes dominantes no total das operações com divisas, o que se explica pelo fato de que entre eles verifica-se intensa concentração dos negócios com câmbio em diversos espaços nacionais. Os dez bancos mais ativos a operarem no mercado cambial londrino, em 1998, foram responsáveis por $50 \%$ das transações, um crescimento de seis pontos percentuais em relação a 1995 (BANK OF ENGLAND, 1998). Mercados como o de Nova Iorque e o de Tóquio mostram-se do mesmo modo cada vez mais concentrados. Em ambos, os dez mais ativos bancos em negócios cambiais ampliaram sua participação, entre 1992 e 1998, de 41 para 51\% (FRBNY, 1998) e de 44 para 64\% (BANK OF JAPAN, 1998), respectivamente. Mesmo os mercados de pequeno porte vêm apresentando uma tendência à concentração sob a égide dos grandes bancos globais. Em Portugal, os quatro maiores operadores respondem por 45 a 50\% das transações diárias (EUROMONEY RESEARCH GUIDES. The 1995 Guide to Portugal. Sept. 1995). O mesmo ocorre na Grécia, onde seis bancos transacionam mais da metade dos recursos que giram diariamente nos mercados à vista e de futuros (EUROMONEY RESEARCH GUIDES. The 1995 Guide to Greece. Sept. 1995)

A própria expansão e a internacionalização, bem como a sofisticação e a complexificação dos mercados cambiais nos últimos anos, podem ser possíveis explicações para o fenômeno da concentração dos negócios com divisas. Com elas, os agentes dispostos a operarem em mercados de câmbio procuram parceiros capazes de lhes proverem, em um único "pacote", ampla gama de serviços bancários e possibilidades de negócios cambiais.

Outro fator a reforçar tal concentração origina-se de particularidades envolvidas com os fundos de pensão, que vêm ampliando, em anos recentes, sua participação nas transações cambiais. Muitos desses fundos são obrigados, por normas estabelecidas em seus estatutos, a operarem apenas com bancos tradicionais e bem avaliados pelo mercado; em termos práticos, os que recebam as notas máximas (os tradicionais triplos A) das agências de classificação e avaliação de risco e solidez financeira, portanto, em sua maioria, com os grandes bancos que operam internacionalmente nos mercados de moedas. ${ }^{18}$

18 Nos EUA, por exemplo, de 1992 a 1995, entre os vinte maiores market makers, o grupo dos bancos que ascenderam posições apresentou uma taxa média de avaliação de risco superior àquele grupo de bancos que as perderam, isto é, os bancos em média melhor avaliados pelas agências de rating tendem a conquistar maior número de clientes (FRBNY, 1995, p. 7). 
Por outro lado, como aponta o BIS (1996a), essa concentração não pode ser interpretada como sinal de redução de competição pelos negócios cambiais entre esses grandes bancos. Como mostra a tabela 4 abaixo, percebese intensa variação no tocante à disposição de negócios tão-somente entre os maiores bancos operadores com divisas. ${ }^{19}$ Eles competem, simultânea e intensamente, em diversos mercados cambiais nacionais, formando um verdadeiro oligopólio global e concentrando, entre eles, a maior parte dos negócios com divisas. Estimativas realizadas em 1996 apontaram que 80\% do volume diário de transações cambiais - US\$ 1,4 trilhão - concentravamse nas mãos de vinte dos principais “jogadores", isto é, dos megabancos globais (Euromoney, May 1996, p. 67).

Uma maneira alternativa de verificar a ascensão dos grandes bancos com estratégia global nos negócios de moedas é por meio da análise da participação das instituições bancárias estrangeiras nos mercados de câmbio nacionais. Em Londres, elas foram responsáveis por $85 \%$ do giro diário em abril de 1998, e, em Tóquio, por 57\%, aprofundando o processo de internacionalização destes mercados cambiais. ${ }^{20}$

Tabela 4 - OS DEZ MAIORES OPERADORES DO MERCADO CAMBIAL GLOBAL, EM 1998.

\begin{tabular}{|c|c|c|c|c|}
\hline CLASSIFICAÇÃO & BANCO & \multicolumn{3}{|c|}{$\begin{array}{c}\text { PARTICIPAÇÃO ESTIMADA } \\
(\%)\end{array}$} \\
\hline$(1)^{*}(1)^{* *}$ & Citibank & 8,54 & $(8,30)$ & $(9,10)$ \\
\hline (4) (9) & Deutsche Bank & 5,57 & $(4,79)$ & $(2,78)$ \\
\hline $3 \quad$ (5) (2) & Chase Manhattan & 4,78 & $(4,65)$ & $(9,04)$ \\
\hline 4 (8) (14) & Goldman Sachs & 4,04 & $(3,82)$ & $(1,79)$ \\
\hline (9) (3) & HSBC & 4,00 & $(3,24)$ & $(6,50)$ \\
\hline (7) (5) & JP Morgan & 3,05 & $(4,40)$ & $(4,22)$ \\
\hline (6) (10) & SBC Walburg Dillon Read & 2,69 & $(4,43)$ & $(2,59)$ \\
\hline $8 \quad$ (3) (24) & Merrill Lynch & 2,65 & $(5,18)$ & $(1,16)$ \\
\hline $9 \quad(2) \quad(4)$ & NatWest & 2,60 & $(5,62)$ & $(4,90)$ \\
\hline 10 (35) (nd) & Industrial Bank of Japan & 2,53 & (nd) & (nd) \\
\hline
\end{tabular}

FONTE: Euromoney, May 1998; May 1997, p. 66; May 1996, p. 60.

NOTAS: * e ** entre parênteses, na primeira coluna, a posição atual e, na última coluna, a participação do banco nos anos de 1997 e 1996, respectivamente.

19 Nos EUA, do grupo dos cinco maiores bancos, em 1995, somente três continuavam a pertencer a este grupo em 1998 (FRBNY, 1998, p. 2).

20 Dados do Bank of England (1998) e do Bank of Japan (1998), respectivamente. 
A concorrência acirrada entre os grandes bancos globais pelos negócios cambiais também relaciona-se a uma das principais características dos mercados de moedas: a de que seus market makers (em geral, estes mesmos grandes bancos globais), pela própria natureza descentralizada e competitiva destes mercados, não estão obrigados a tornar públicos os termos, de preço e de quantidade, nos quais são efetivamente fechadas as transações cambiais. Não há plena circulação das informações necessárias para a consecução perfeitamente segura das transações, de acordo com as condições prevalecentes no mercado, a cada momento do tempo. O market maker está sujeito ao risco de efetivar negócios fora dos parâmetros mais atualizados do mercado. Para reduzir esse risco, ele precisa estar constantemente coletando informações junto a outros agentes, especialmente outros market makers, e consegue efetivar isso estabelecendo trocas de moedas com os mesmos. Quanto mais operações realizar, melhor "informado" estará o banco quanto às condições correntes do mercado, tornando-se, na disputa concorrencial com outros bancos, mais capaz de garantir seu "espaço de valorização do capital". Nesses termos, os bancos são impelidos a ampliar sua participação nos negócios cambiais, pois estes apresentam uma espécie de economias crescentes de escala no tocante à captação de informações.

Há um outro aspecto pertinente dessa relação entre concentração das operações cambiais nas mãos de grandes bancos e os fluxos de informações nos mercados de divisas. Com tal concentração, limita-se o número de agentes relevantes para a definição das condições do mercado que filtram as eventuais novas informações ou eventos que, de alguma forma, relacionam-se com o mercado de divisas. Diminui-se, assim, a capacidade do mercado, pela própria dispersão e diversidade de interpretações sobre tais informações ou eventos, de diluir os potenciais impactos destes sobre as paridades cambiais concernentes. Por outro lado, não se pode descartar a possibilidade de essa concentração dos negócios de câmbio nas mãos de poucos agentes estabelecer novos parâmetros para a intervenção dos bancos centrais nos mercados de câmbio. ${ }^{21}$ Afinal, os bancos centrais podem, até certo limite e através de "persuasão moral", convencer os principais bancos a assumirem determinadas posições nos mercados de moedas.

21 Quanto à discussão dos efeitos da intervenção dos bancos centrais sobre o comportamento das taxas de câmbio, sugere-se HUMPAGE (1996) e DOMINGUEZ (1998). 


\section{Novos AGENTES}

Embora os bancos globais sejam os principais agentes a operar atualmente nos mercados cambiais, grande parte dos recursos que transitam nestes mercados não pertence, de fato, aos bancos, mas sim aos seus clientes: instituições não-financeiras (empresas comerciais e industriais) e instituições financeiras não-bancárias, em especial os denominados investidores institucionais, com "horizonte global" de aplicação da riqueza. Estes investidores (fundos de pensão, fundos mútuos de investimento e companhias de seguro), ${ }^{22}$ pelo significativo e crescente volume de recursos que administram, representam um dos aspectos mais destacados nas análises sobre os mercados financeiros internacionais. Outros clientes importantes dos serviços e produtos cambiais ofertados pelos bancos são as tesourarias de grandes corporações, os fundos de hedge etc. ${ }^{23}$

Muitas mudanças e definições do comportamento dos mercados podem originar-se das decisões estratégicas tomadas por esses investidores quanto à composição de suas carteiras, com os bancos apenas agindo a reboque, amortecendo-as ou intensificando-as. Isso significa uma mudança em relação ao passado, quando os próprios bancos, em certos casos agindo isoladamente, conseguiam impor a dinâmica nos movimentos cambiais. Nas palavras de um banqueiro do Sumitomo Bank, "dez anos atrás, um dealer podia mover o mercado; agora são os fundos de hedge e fundos de pensão que estabelecem os passos (do mercado cambial)." (Euromoney, May 1997, p. 64)

A ampliação de ativos estrangeiros nas carteiras dos investidores institucionais, o que por si só os fazem demandar maiores serviços cambiais junto aos bancos, coloca esses investidores frente a uma forma específica de risco: o risco cambial. Para protegerem-se deste, precisam efetuar operações de hedge nos mercados futuros de moedas, geralmente intermediadas pelos

22 Os fundos de pensão americanos, japoneses e britânicos mantinham, em 1993, o montante de 5,4 trilhões de dólares em ativos financeiros (MEKKAOUI, 1997, p. 39). FISCHER e REISEN (1994, p. 9) estimam que, no ano 2000, fundos de pensão dos países da OCDE administrarão mais de 12 trilhões de dólares. Por sua vez, o Fundo Monetário Internacional estimou que em 1994 os fundos de pensão, as companhias seguradoras e os fundos mútuos dos países da OECD administravam, no total, uma riqueza de US\$ 20 trilhões (FOLKERTS-LANDAU et al., 1997, p. 33).

23 Sobre as características dos fundos de hedge e de suas operações, ver GOLDSTEIN e FOLKERTS-LANDAU, 1994, p. 6-9. 
bancos. Em certos países, Itália e Alemanha, por exemplo, existe legislação específica obrigando os investimentos em ativos estrangeiros a serem "cobertos" por operações redutoras dos riscos cambiais neles envolvidos, com o objetivo de manter alinhada a composição cambial dos ativos com a dos passivos. Mas cada decisão de operação no mercado de derivativos cambiais, mesmo com a finalidade de cobertura de riscos de moeda, tomada pelos clientes dos bancos, obriga estes últimos a realizarem outras operações de derivativos, agora para eles próprios protegerem-se dos riscos de câmbio, proporcionado pelo desequilíbrio em seus balanços (KREGEL, 1994). ${ }^{24}$

Alguns dos investidores institucionais e, principalmente, os administradores de fundos mútuos ou de hedge não operam nos mercados de moedas, à vista ou de derivativos, apenas como a contraparte das compras e vendas de ativos financeiros estrangeiros. Eles consideram o próprio mercado cambial uma alternativa de investimentos e de ampliação da riqueza monetária, tratando as moedas como uma forma particular de ativo financeiro. Assim, muitas das operações com derivativos cambiais são realizadas não com o intuito de fornecerem proteção a algum agente, mas sim como mais um mercado do qual se pode auferir ganhos financeiros, operando com um ativo (o derivativo) mais líquido e com menores custos de transação que os ativos que lhe são subjacentes.

Por outro lado, existem fundos voltados de maneira exclusiva para os mercados cambiais. Adotam uma postura puramente especulativa ao assumirem posições cambiais, em especial via derivativos, com elevadas taxas de alavancagem. ${ }^{25} \mathrm{Com}$ isso, visam auferir ganhos decorrentes da volatilidade das taxas de câmbio, tentando prognosticar a direção das futuras flutuações dos valores relativos entre as divisas. Ironicamente denominados de fundos de hedge, muitos deles de fato representam alternativas de aplicação que, embora prometam elevados ganhos, carregam altos riscos, atraindo assim somente aplicadores dispostos a assumi-los e que, possuindo grande monta de recursos, empregam uma margem destes em investimentos com presumida alta taxa de rentabilidade.

24 Estima-se que cada transação cambial de um banco com um cliente nãobancário redunde de quatro a cinco operações no interbancário (GOLDSTEIN et al., 1993, p. 5), contribuindo, assim, para inflar o volume de negócios no interior dos mercados de câmbio.

25 Segundo avaliação do FMI, os agentes de conotação eminentemente especulativa possuem mais de US\$ 100 bilhões em ativos e conseguem realizar aplicações "alavancando" de cinco a dez vezes o valor de seus ativos (FOLKERTS-LANDAU et al., 1997, p. 33). 
Os grandes bancos globais afirmam ser importante para eles intermediarem as operações desses novos agentes, mesmo que elas, por si só, não sejam muito lucrativas, em termos de spreads ou comissões recebidos. Declaram os administradores dos negócios cambiais dos grandes bancos que se relacionar com os investidores institucionais e fundos de moedas significa dispor do acesso a importantes fluxos de informações (não livres a todos os participantes), necessários para as tentativas de compreensão dos movimentos presentes e de estimação das tendências futuras do mercado. Afinal, tal compreensão e estimação fornecem subsídios fundamentais para estes bancos tomarem suas próprias posições no mercado de divisas, não apenas aquelas referentes aos preços (cotações) de compra e venda das moedas, mas também as relativas à composição dos seus estoques de divisas, de modo a torná-los, ex ante, mais condizentes com as estratégias de valorização da riqueza que tenham assumido. Nas palavras do responsável pelas transações cambiais do Citibank, em Londres,

É muito importante para nós observarmos os fluxos [cambiais]. É comum serem os bancos que tomam as grandes posições, mas, com o intuito de compreender o mercado hoje, você precisa saber para onde o dinheiro dos investidores institucionais está indo e quais serão os efeitos disso no médio prazo. Isso permite-nos tomar posições de troca mais agressivas. (Euromoney, Jan. 1994, p. 49).

O diretor dos negócios cambiais do Swiss Bank confirma: "A informação dos fluxos de negócios (de câmbio) é imperativa" (Euromoney, Jan. 1994, p. 49). Por conta disso, os agentes que nele operam são impelidos a estar efetuando, permanentemente, transações entre si, em especial se desejam assumir "posições de troca mais agressivas", de forma, inclusive, a impor, sobre o mercado, suas interpretações quanto aos "corretos" valores das paridades entre as moedas, ganhando vantagens sobre seus concorrentes ou evitando perdas desnecessárias.

\section{COMENTÁRIOS FINAIS}

Apresentou-se aqui alguns aspectos do mercado cambial global, com o intuito de delinear um quadro geral sobre a conformação atual deste mercado, pondo em evidência algumas relações entre a sua estrutura e o seu 
funcionamento. Muitos de tais aspectos (o crescimento das operações intradiárias, a atuação dos investidores institucionais e dos fundos de hedge, o crescente uso de derivativos cambiais, a crescente interconexão dos mercados) permitem pressupor a ascensão, nos últimos anos, do mercado internacional de moedas à condição de um caso particular de mercado financeiro global. Por outro lado, como afirmam economistas de diferentes posições teóricas, tais como HARVEY (1995) e OBSTFELD (1994), o tamanho e a forma como o mercado cambial global está atualmente estruturado fomentam a volatilidade e os desalinhamentos crônicos das principais taxas de câmbio, caracterizando-o como um mercado potencialmente instável. Indo além, as transformações pelas quais este mercado tem passado nos últimos anos acirraram-lhe o caráter já instável decorrente de seu arranjo microeconômico e, condicionados por este, dos comportamentos dos agentes nele atuantes.

Pela sua própria e atual conformação estrutural e operacional, os mercados de câmbio possuem um risco sistêmico potencial muito superior ao simples somatório dos riscos presumidos pelos agentes envolvidos em cada operação cambial - riscos geralmente tidos por estes como minimizados ou delimitados por operações de cobertura através de derivativos -, que quando eclode gera fortes pressões especulativas sobre algumas divisas e, no limite, desmonta arranjos cambiais domésticos e impõe pesadas penas sobre a economia como um todo. Por esse e outros aspectos, é necessário para a compreensão da dinâmica dos mercados de câmbio modernos e dos fenômenos a ele relacionados investigar, com maior atenção, o leitmotif e os condicionantes estruturais/operacionais nos quais se dão as ações dos diferentes agentes e os mecanismos e canais nos quais estes interagem e se confrontam no mercado.

\section{RESUMO}

Este artigo busca sintetizar algumas das principais características e transformações estruturais do mercado internacional de câmbio na última década. O intuito é apontar como os fatores, que fizeram o volume de recursos a circular diariamente neste mercado crescer a taxas elevadas nos últimos dez anos, podem ter também responsabilidade pelos períodos de volatilidade e desalinhamento cambial e pela emergência mais frequiente de casos de crises cambiais na década de noventa. 


\begin{abstract}
This paper synthesizes some of the main characteristics and structural changes that took place in the international exchange market in the last decade. Its aim is to show how the same causes that made the international amount of resources circulating daily in that market increase significantly in the last ten years, may have also some responsibility for the periods of exchange volatility and disarray, and for the increased frequency of exchange crises in the 1990's.
\end{abstract}

\title{
REFERÊNCIAS
}

AGLIETTA, M. La fin des devises-clés. Paris: La Découverte, 1986.

A CLOSE Chase. Euromoney, p. 60-70, May 1996.

A TOUGH race gets tougher. Euromoney, p. 53-69, May 1998.

BANK FOR INTERNATIONAL SETTLEMENTS. Central bank survey of foreign exchange and derivatives market activity in April 1998: Preliminary global data. Basiléia, 1998. .67th annual report. Basiléia, 1997.

. Central bank survey of foreign exchange and derivatives market activity. Monetary and Economic Departament. Basiléia, 1996a.

67th annual report. Basiléia, 1996b.

BANK OF ENGLAND. The UK foreign exchange and over-the-counter derivatives markets in April 1998. Londres, 1998.

BANK OF JAPAN. Foreign exchange and derivatives markets turnover survey (April 1998). Tókio, 1998.

BURNHAM, J. B. Current structure and recent developments in foreign exchange markets. In: KHOURY, S. J. (Ed.). Recent developments in International Banking and Finance. Elsevier: North Holland, 1991.

CANUTO, O.; LAPLANE, M. Especulação e instabilidade na globalização financeira. Economia e Sociedade, n. 5, p. 31-60, dez. 1995.

COUTINHO, L. G.; BELLUZZO, L. G. de M. Desenvolvimento e estabilização sob finanças globalizadas. Economia e Sociedade, n. 7, p. 129-154, dez. 1996.

DE GRAUWE, P.; DECUPERE, D. Psychological barriers in the foreign exchange market. Discussion Paper. Londres: Centre for Economic Policy Research, 1992. n. 621.

DOMINGUEZ, K. M. Central bank intervention and exchange rate volatility. Journal of International Money and Finance, v. 17, n. 1, p. 161-190, 1998.

EICHENGREEN, B.; ROSE, A.; WYPLOSZ, C. Exchange market maythem: the antecendents and aftermath of speculative attacks. Economic Policy, v. 21, n. 2, p. 251-312, 
1995.

Speculative attacks on pegged exchange rates: an empirical exploration with special reference to the European Monetary System. NBER Working Papers, n. 4898, 1994.

; WYPLOSZ, C. The unstable EMS. Brookings Papers on Economic Activity, n. 1, p. 51-124, 1993.

EUROMONEY RESEARCH GUIDES. Vários números.

FEDERAL RESERVE BANK OF NEW YORK. April 1995 survey of foreign exchange market activity in the United States. New York, 1995. n. 1, versão revisada.

FIELEKE, N. S. Foreign-currency positioning by U. S. firms: some new evidence. Review of Economics and Statistics, v. 63, n. 1, p. 35-42, 1981.

FISCHER, B.; REISEN, H. Pension fund investment from ageing to emerging markets. Policy Brief, Paris, OECD Development Centre, n. 9, 1994.

FLOOD, M. D. Market structure and inefficiency in the foreign exchange market. Journal of International Money and Finance, v. 13, n. 2, p. 131-158, 1994.

FLOOD, R. P.; GARBER, P. M. Gold monetization and gold discipline. Journal of Political Economy, v. 92, p. 90-107, Feb. 1984a.

. Collapsing exchange-rate regimes: some linear examples. Journal of International Economics, v. 17, n. 1-2, p. 1-13, 1984b.

FOLKERTS-LANDAU, D.; MATHIESON, D. J.; SCHINASI, G. J. International capital markets: developments, prospects, and key policy issues. Washington: World Economic and Financial Surveys; Fundo Monetário Internacional, 1997.

FOLLOW those funds - see the flows. Euromoney, p. 49-54, Jan. 1994.

; ITO, T. et al. International capital markets: developments, prospects, and policy issues. Washington: World Economic and Financial Surveys; Fundo Monetário Internacional, 1995.

FRANKEL, J. A. Tests of rational expectations in the forward exchange market. In: GALLI, G.; GIOVANNINI, A. (Ed.). The microstructure of foreign exchange markets. Chicago: The University of Chicago Press, 1993.

; FROOT, K. A. Chartists, fundamentalists, and trading in the foreign exchange market. The American Economic Review, v. 80, n. 2, p. 181-185, 1990.

; ROSE, A. K. Currency crashes in emerging markets: an empirical treatment. International Finance Discussion Papers, Board of Governors of the Federal Reserve System, n. 534, Jan. 1996.

FRIEDMAN, M. The case for flexible exchange rates. In: FRIEDMAN, M. (Ed.). Essays in positive economics. Chicago: Chicago University Press, 1953.

FROOT, K. A.; THALER, R. H. Anomalies: foreign exchange. Journal of Economic Perspectives, v. 4, n. 3, p. 179-182, 1990.

GARBER, P. M. Derivatives in international capital flows. NBER Working Papers, n. 6625, 1998.

; SPENCER, M. G. Foreign exchange hedging and interest rate defense. Interna- 
tional Monetary Fund Staff Papers, v. 42, n. 3, p. 490-516, 1995.

GERLACH, S.; SMETS, F. Contagious speculative attacks. Working Paper, Basiléia, Bank for International Settlements, n. 22, Sept. 1994.

GOLDSTEIN, M.; FOLKERTS-LANDAU, D. International capital markets: developments, prospects, and policy issues. Washington: World Economic and Financial Surveys; Fundo Monetário Internacional, 1994.

et al. International capital markets: part 1. Exchange rate management and international capital flows. Washington: World Economic and Financial Surveys; Fundo Monetário Internacional, 1993.

GOODHART, C. The foreign exchange market: a random walk with a dragging anchor. Economica, v. 55, n. 220, p. 437-460, 1988.

GRABBE, J. O. International financial markets. New Jersey: Prentice-Hall, 1996.

HARVEY, J. T. The international monetary system and exchange rate determination: 1945 to the present. Journal of Economic Issues, v. 29, n. 2, p. 493-502, 1995.

; QUINN, S. F. Expectations and rational expectations in the foreign exchange market. Journal of Economic Issues, v. 31, n. 2, p. 615-622, 1997.

HSIEH, D. A.; KLEIDON, A. W. Bid-ask spreads in foreign exchange markets: implications for models of asymmetric information. In: FRANKEL, J. A.; GALLI, G.; GIOVANNINI, A. (Ed.). The microstructure of foreign exchange markets. Chicago: The University of Chicago Press, 1993.

HUMPAGE, O. F. Are successful interventions random events? Economic Commentary, n. 1, Mar. 1996.

ITO, T. Foreign exchange rate expectations: micro survey data. The American Economic Review, v. 80, n. 2, p. 434-449, 1990.

; FOLKERTS-LANDAU, D. et al. International capital markets: developments, prospects, and key policy issues. Washington: World Economic and Financial Surveys; Fundo Monetário Internacional, 1996.

JORION, P. Risk and turnover in the foreign exchange market. In: FRANKEL, J. A.; GALLI, G.; GIOVANNINI, A. (Ed.). The microstructure of foreign exchange markets. Chicago: The University of Chicago Press, 1993.

KREGEL, J. A. Global portfolio allocation, hedging, and September 1992 in the European Monetary System. In: DAVIDSON P.; KREGEL, J. (Ed.). Employment, growth, and finance: economic reality, and economic growth. Aldershot: Edward Elgar, 1994.

KRUGMAN, P. A model of balance-of-payments crises. Journal of Money, Credit, and Banking, v. 11, n. 3, p. 311-325, 1979.

; MILLER, M. Why have target zone? Carnegie-Rochester Conference Series on Public Policy, v. 38, p. 279-314, June 1993.

LYONS, R. Tests of microstructural hypotheses in the foreign exchange market. Journal of Financial Economics, v. 39, p. 321-351, 1995.

MEKKAOUI, N. El. Comportements financiers des fonds de pension dans les pays de l'OCDE. Économie Internationale, n. 70, p. 35-55, 1997.

OBSTFELD, M. Models of currency crises with self-fulfilling features. European Eco- 
nomic Review, v. 40, n. 3/5, p. 1037-1048, 1996.

The logic of currency crises. NBER Working Papers, n. 4640, 1994.

Rational and self-fulfilling balance of payments crises. The American Economic Review, v. 76, n. 1, p. 72-81, 1986.

Balance-of-payments crises and devaluation. Journal of Money, Credit and Banking, v. 16, n. 2, p. 208-217, 1984.

; ROGOFF, K. The mirage of fixed exchange rates. Journal of Economic Perspectives, v. 9, n. 4, p. 73-96, 1995.

OZKAN, F. G.; SUTHERLAND, A. Policy measures to avoid a currency crises. Economic Journal, v. 105, n. 429, p. 510-519, 1995.

ROMO, H. G. Globalización financiera y riesgo sistémico. Comercio Exterior, v. 47, n. 11, p. 870-880, nov. 1997.

ROSE, A.; SVENSSON, L. E. O. European exchange rate credibility before the fall. European Economic Review, v. 38, n. 6, p. 1185-1216, 1994.

SHASTRI, K.; SULTAN, J.; TANDON, K. The impact of the listing of options in the foreign exchange market. Journal of International Money and Finance, v. 15, n. 1, p. 37-64, 1996.

TAKEN aback by a leap forward. Euromoney, p. 61-76, May 1997.

TAYLOR, M. P.; ALLEN, H. The use of technical analysis in the foreign exchange market. Journal of International Money and Finance, v. 11, n. 3, p. 304-314, 1992.

WYPLOSZ, C. Capital controls and balance of payments crises. Journal of International Money and Finance, v. 5, n. 2, p. 167-179, 1986.

WHEN is a market like treacle? Euromoney, p. 155-156, July 1996. 